\title{
Changes in the quality of life of female participants from the University of the Third Age and their predictors
}

A - preparing concepts

B - formulating methods

$\mathrm{C}$ - conducting research

$\mathrm{D}$ - processing results

E - interpretation and conclusions

$\mathrm{F}$ - editing the

final version

Received: 2019-02-20

Accepted: 2019-05-16

\author{
Anna Leś ${ }^{A-F}$, Monika Guszkowska ${ }^{A-F}$, Ewa Kozdrońn ${ }^{A-B}$, \\ Joanna Piotrowska ${ }^{A-B}$, Ewa Niedzielska ${ }^{A-B}$, Bartłomiej Krynicki ${ }^{A-B}$ \\ Józef Piłsudski University of Physical Education in Warsaw
}

https://doi.org/10.5114/areh.2019.87745

\begin{abstract}
:
Introduction: Quality of life is identified as a key element in healthy ageing. A decrease in physical activity and fitness levels as well as fear or depression increase the frequency of hospitalisation and mortality rate among elderly persons. Moreover, these factors significantly reduce the quality of life. The aim of the study was to determine changes in elderly women's perception of their quality of life that occurred over a period of 3 months of attending regular classes. In addition, the study sought to identify factors that would make it possible to predict these changes.

Material and methods: The study included 56 women aged 58 to $85(\mathrm{M}=69.54$; $\mathrm{SD}=6.578$ ). Their quality of life was assessed with an abbreviated version of WHOQOL -Bref questionnaire. Severity of depressive symptoms was examined with the use of the Geriatric Depression Scale (a 15-item version). In order to determine physical fitness levels, FFF Test was carried out.

Results: The examined group manifested changes in the depression indicator, i.e. its levels decreased significantly. A considerable increase in self-rated health was observed. There occurred a significant increase in the women's perception of their quality of life in social and environmental domains. No significant changes in the quality of life were noted in physical and psychological domains as well as in overall satisfaction with the quality of life.

Conclusions: The findings suggest that attending classes at the UTA may produce benefits in the field of psychological health and life quality, and their scope may depend on the initial state of physical health and physical fitness.
\end{abstract}

Key words: $\quad$ Geriatric Depression Scale, quality of life questionnarie, physical fitness levels, elderly women's perception

\section{Introduction}

Research on the quality of life and its determinants (including the role and significance of regular physical activity in improving life quality) has been carried out since the 1990s [1]. According to Karimi and Brazier [2], from a psychological standpoint, quality of life is understood as 'satisfaction with life'. Defining overall life satisfaction is a difficult task both for study participants and researchers (when developing measurement tools). It seems that it is better to analyse the quality of life in terms of specific areas that are significant in human life (e.g. health, social relations, physical fitness, daily physical activity, activities of daily living, professional activity). According to the definition of health put forward by the World Health Organization (WHO), domains associated with physical, psychological and social well-being are basic elements in life quality assessment [3].

email: les.anna@wp.pl 
Self-rated health and other domains are significant elements of this concept. Self-assessment is often used in research on life quality. The quality of life is identified as the key element in healthy ageing [4]. There are many determinants of life quality in elderly persons such as: health, family and social relations, financial situation, autonomy in everyday life, attitude to life as well as health of the relatives [5-11]. In the quality of life assessment, health and its elements (especially a feeling of comfort/ well-being, being fit, emotional and intellectual functioning as well as participation in social life) play a key role. However, we need to bear in mind that some elderly individuals perceive their life as satisfactory despite health issues $[10,12]$. It may stem from the fact that other factors affecting life quality compensate for health problems. In seniors, a phenomenon of adapting to the limit of health is observed. Moreover, a sense of lower importance of health when assessing quality of life can be noted $[7,10]$. Alongside the advancement in age, psychological changes are more noticeable. These changes are closely associated with the changes in physical, health-related and social spheres. Senior persons become more dependent on their nearest environment and they need more security. They begin to demonstrate symptoms of hypochondria and social prejudices and they exhibit lower selfesteem [13].

Elderly persons often report lower levels of life quality. It may be related to a decrease in daily physical activity as well as affective problems such as fear or depression. A sedentary lifestyle significantly increases the risk of health deterioration (including the risk of cardiovascular diseases or depression). Depression, which is the second most significant psychopathological syndrome, is one of the main geriatric problems. Its risk factors in older age include health-related issues and the death or disease of a close person [12,13]. Reduced daily physical activity, lower levels of physical fitness, fear and depression increase hospitalisation frequency and mortality rate among the elderly. These factors significantly decrease their perception of the life quality [14].

Social involvement and interactions (not only between family members but also with individuals other than the closest ones) greatly influence on perceived quality of life [15]. One of the ways of involving elderly persons in social activities is to promote the notion of lifelong learning. Individuals over 65 years of age may satisfy their need for by studying in a friendly environment with others. Doing so helps elderly persons understand the world better, develop social relations and maintain current activity levels. Moreover, it improves their overall quality of life, which translates into better mood, better understanding of oneself, and feeling included as members of society. An important role in promoting lifelong learning among senior citizens is played by Universities of the Third Age (UTAs), schools specialized in educating elderly persons $[16,17]$.

The aim of the study was to determine changes in perceived quality of life in elderly women (UTA students) over a period of 3 months of regular classes. Furthermore, the study sought to identify factors (among demographic variables as well as among those that refer to health state, physical fitness and perception ability) that would make it possible to predict these changes.

\section{Material and methods}

A person over 55 years of age who has presented a medical certificate confirming the absence of health contraindications to engage in physical activity may become a UTA member. Recruitment for classes in the UTA takes place twice a year (September and February). The project involved women who voluntarily agreed to participate in the research and regularly participated in classes. The study included 56 women aged 58 to $85(\mathrm{M}=69.54$; $\mathrm{SD}=6.578$ ) who mostly had secondary or higher education (46.4\% and $41.1 \%$, respectively). Almost half of the study participants $(46.5 \%)$ were married, while the remaining women were widows $(32.1 \%)$, divorcees $(12.5 \%)$ and singles ( $8.9 \%)$. The majority of the examined women declared that they had chronic diseases $(73.2 \%)$ and took medications on a regular basis $(67.9 \%)$.

\section{Research tools}

Results obtained with the use the WHOQOLBref questionnaire as well as responses to questions regarding overall perception of life quality and health, self-rated health (visual scale) and scores from the depression scale (negative indicators of life quality) were the indicators of the quality of life.

WHOQOL-Bref is a research tool used to assess the quality of life in healthy and ill individuals. It's used both for cognitive and medicinal purposes. It 
allows researchers to obtain a life quality profile in the following four domains: physical health, psychological health, social relationships and the environment. Moreover, the scale includes items (questions) that are analysed separately: question 1 (Q1) regarding an individual perception of overall quality of life, and question 2 (Q2) concerning an individual perception of general health. The scores in the above-mentioned domains reflect an individual perception of life quality in these areas. The higher the score, the higher the quality of life.

The study participants self-rated their health state on a visual scale of 0-100 (so-called health thermometer).

The Geriatric Depression Scale developed by Yesavage (a 15-item version) was employed to assess severity of depressive symptoms. The scale consists of 15 items describing basic symptoms of depression. The questions, which refer to the occurrence of symptoms in the last two weeks, are answered 'yes' or 'no'. Scores within a range of 11-15 indicate severe depression, while scores of 6-10 are indicative of moderate depression.

Moreover, the authors' own questionnaire was used. It provided data on the participants' age, education, marital status, financial situation, chronic diseases and medications taken. Blood pressure and heart rate at rest were used as health state indicators.

In order to determine physical fitness levels, Fullerton's Functional Fitness Test was carried out. The test is comprised of 6 individual test items:

1. Arm Curl - measurement of upper body muscle endurance.

2. 30-second Chair Stand - measurement of lower body strength.

3. Back Scratch Test - measurement of upper-body flexibility.

4. Chair Sit and Reach Test - measurement of lower-body flexibility (specifically hamstring flexibility).

5. 8-Foot Up and Go - measurement of agility (dynamic balance) and aerobic endurance.

6. 2-Minute Step in Place Test - measurement of (aerobic) endurance. It is performed when it is not possible to do the 6-Minute Walk Test.

In addition, a dynamometer was used to measure hand grip strength. The Romberg static balance test was also carried out under eyes-open and eyesclosed conditions.

To assess perception abilities, the Attention and Perceptiveness Test (version 3/8) developed by
Ciechanowicz and Stańczak was employed. The test provides indicators of perception speed (the number of analysed signs), unreliability of perception (number of mistakes) and unreliability of attention (number of omissions). Standard performance conditions were applied (duration - approx. 3 minutes).

All the examinations were conducted twice, i.e. at the beginning of the semester and after three months of participating in UTA classes.

In order to determine significance of changes over time, the Student's t-test for dependent samples was used. Correlations between variables were defined with the use of the Pearson correlation coefficient, whereas predictors of changes in life quality were established using the stepwise regression analysis. Statistica 13.3 was used for statistical analysis (StatSoft, Inc. USA). Statistical significance was set at the level of $\mathrm{p} \leq 0.005$.

\section{Results}

The participants of the project were 56 women aged between 58 and $85(\mathrm{M}=69.54 ; \mathrm{SD}=6.578)$ attending UTA lectures at the University of Physical Education in Warsaw. The majority of participants had tertiary education $(41.1 \%), 46.4 \%$ had secondary education. As for their marital status, 46.5\% were married, $32.1 \%$ were widowed, $12.5 \%$ were divorced, and $8.9 \%$ were single. Almost half lived alone $(44.8 \%)$ and almost as many (46.2\%) lived with their husbands, with the remaining 9\% living with other family members. Thirty-nine percent described their financial situation as average, $37.7 \%$ as comfortable, $10.4 \%$ as either very comfortable or bad, and only $2.6 \%$ as very bad. More than twothirds of participants $(73.2 \%)$ had chronic health conditions, and $67.9 \%$ took regular medication.

\section{Changes in the quality of life}

The following elements were used as life quality indicators: total scores on the quality of life scale in the domains of physical health, psychological health, social relationships and environment (WHOQOL-Bref), responses to detailed questions regarding satisfaction with life and health, selfrated health on a visual scale and the score on the Geriatric Depression Scale. Results of the first and second measurement are presented in table 1. 
Tab. 1. Quality of life measured at the beginning and at the end of semester

\begin{tabular}{|c|c|c|c|c|c|c|}
\hline \multirow{2}{*}{$\begin{array}{l}\text { Measurement } \\
\text { Variable }\end{array}$} & \multicolumn{2}{|c|}{ Measurement I } & \multicolumn{2}{|c|}{ Measurement II } & \multicolumn{2}{|c|}{ Student's t-test } \\
\hline & M & SD & M & SD & $\mathrm{t}$ & $\mathrm{p}$ \\
\hline QOL - physical health & 26.05 & 4.708 & 26.98 & 8.145 & 0.843 & n.s. \\
\hline QOL - psychological health & 21.93 & 3.541 & 22.66 & 3.806 & 1.208 & n.s. \\
\hline QOL - social relationships & 10.44 & 1.864 & 11.31 & 1.980 & 3.250 & 0.002 \\
\hline QOL - environment & 29.66 & 4.345 & 30.98 & 4.433 & 2.203 & 0.032 \\
\hline Satisfaction with life quality & 3.77 & 0.539 & 3.84 & 0.654 & 0.683 & n.s. \\
\hline Satisfaction with health & 3.43 & 0.759 & 3.63 & 0.822 & 1.628 & n.s. \\
\hline Self-rated health & 69.00 & 13.351 & 75.36 & 16.289 & 2.634 & 0.011 \\
\hline Depression & 3.70 & 1.808 & 2.27 & 1.824 & 4.058 & $<0.001$ \\
\hline
\end{tabular}

The greatest changes were noted in the psychological well-being (a significant decrease in depression symptoms was observed). Furthermore, a significant increase in health rated by the participants on 'the thermometer' was observed. However, no such increase was revealed in the case of overall health satisfaction (as indicated in Q2 from the WHOQOL-Bref). There occurred a significant increase in the quality of life in a social environment. No significant changes were noted in life quality in physical and psychological domains as well as in overall satisfaction with life quality (response to Q1).

In the case of variables in which significant changes were revealed, their indicators were calculated in a way that positive values of an indicator meant a desired change took place. The indicators of the increase in life quality and selfrated health were calculated by subtracting results of the first measurement from the scores in the second measurement. The indicator of the decrease in depression levels was calculated by subtracting results of the second measurement from the results of the first measurement.

Afterwards, correlation coefficients between indicators of changes and demographic variables (age, education, financial situation), indicators of physical health (body mass, blood pressure and heart rate) as well as indicators of physical fitness and perception ability in the first measurement were calculated. No significant correlations between improvement of life quality indicators and self-rated health was observed. Also, there was no important relations between indicators of a reduction in depressive symptoms with age, education and a financial situation. An increase in self-rated health correlated negatively only with systolic blood pressure $(\mathrm{r}=-0.265 ; \mathrm{p}=0.049)$. A decrease in depression levels correlated positively with heart rate at rest $(\mathrm{r}=0.293 ; \mathrm{p}=0.028)$, static balance under eyes-open (left leg: $\mathrm{r}=0.266$; $\mathrm{p}=0048$; right leg: $r=0.253 ; p=0.060$ ) and eyes-closed (right leg: $\mathrm{r}=0.305 ; \mathrm{p}=0.022$ ) conditions. An increase in the quality of life in the social domain correlated negatively with systolic blood pressure $(\mathrm{r}=-0.286$; $\mathrm{p}=0.034$ ) and positively (a tendency) with upperbody flexibility (left hand) $(r=0.243 ; p=0.074)$. Life quality improvement in the environmental domain correlated negatively (no statistical significance was revealed, only a tendency was noted) with diastolic blood pressure $(\mathrm{r}=-0.257 ; \mathrm{p}=0.056)$. Thus, an increase in the indicators of life quality was larger, in the first measurement, when blood pressure was lower and physical fitness levels were higher. No significant correlations with perception ability were noted.

Next, predictors of changes in the quality of life were determined (tab. 2). Variables whose indicators correlated significantly with change indicators were used in the equation. No factor that would make it possible to predict changes in life quality in the environmental domain was determined. In the remaining cases, models were obtained that allowed us to predict a dependent variable to a slight extent only (a few percent). Systolic blood pressure proved to be a negative predictor of an increase in life quality in the social domain and of an increase in self-rated health. A decrease in depression levels may be predicted on the basis of balance levels. A greater improvement in the quality of life may be expected from female senior citizens who had lower systolic blood pressure and manifested higher levels of balance at the beginning of their UTA classes. 
Tab. 2. Predictors of changes in the quality of life

\begin{tabular}{|l|c|c|c|}
\hline Dependent variable & Predictor & beta & $\begin{array}{c}\text { Model } \\
\left(\mathrm{R}^{2}, \mathrm{~F}, \mathrm{p}\right)\end{array}$ \\
\hline $\begin{array}{l}\text { Decrease in depres- } \\
\text { sion levels }\end{array}$ & $\begin{array}{c}\text { Right-leg balance } \\
\text { (eyes closed) }\end{array}$ & 0.305 & $\begin{array}{c}0.076 ; \\
5.551 ; 0.022\end{array}$ \\
\hline $\begin{array}{l}\text { Increase in the } \\
\text { quality of life in the } \\
\text { social domain }\end{array}$ & $\begin{array}{c}\text { Systolic blood } \\
\text { pressure }\end{array}$ & -0.286 & $\begin{array}{c}0.064 ; \\
4.714 ; 0.034\end{array}$ \\
\hline $\begin{array}{l}\text { Increase in self-rated } \\
\text { health }\end{array}$ & $\begin{array}{c}\text { Systolic blood } \\
\text { pressure }\end{array}$ & -0.265 & $\begin{array}{c}0.053 ; \\
4.073 ; 0.049\end{array}$ \\
\hline
\end{tabular}

\section{Discussion}

The findings show an improvement in several indicators of life quality in female UTA students. After three months of regular classes, a decrease in depression levels and an increase in self-rated health and life quality in the social settings were noted. The study participants took part in gymnastics classes (including healthy spine exercises and water gymnastics $-91 \%$ ) as well as Nordic walking and tai-chi classes $(9 \%)$. It is hard to determine which of these classes contributed more to the changes that occurred.

Previous studies show that in elderly persons, there occurs a positive correlation between daily physical activity (DPA), physical fitness and healthrelated quality of life (HRQOL). Regular physical exercises as well as physical activity levels exert a positive influence on perceived quality of life [18-20]. A 12-week programme of aerobic exercises for ageing adults already produced positive outcomes regarding quality of life [12,14]. Moderate physical activity may bring about an improvement in perceived life quality and a reduction in the incidence of risk factors related to depression disorders [4]. Within a period of one month, physically active senior citizens have an average of 14 'unhealthy days' less than their physically inactive peers (self-rated physical and psychological health). Research results point to a significant role of moderate physical activity when it comes to self-rated health, vitality, overall health state and independent functioning on a daily basis [12]. A crucial role is played by a subjective feeling of physical fitness that correlates with quality of life (higher correlations between subjective evaluations and life quality than between objective measurement results of physical activity and fitness and quality of life). Previous studies confirmed that fitness tests (objective assessment of physical fitness levels) correlated with the quality of life only to a certain extent [21]. Mood is the factor that significantly affected perceived life quality of elderly females [14].

In the group of elderly individuals, $15-20 \%$ of the persons experience depression, while among those under medical care, as many as $30 \%$ of the patients suffer from this condition [13]. People with depression consider their life quality to be poor. Moreover, they have difficulties maintaining interpersonal relationships and the risk of contracting infectious diseases is higher [15]. Thus, a decrease in the intensity of depressive symptoms in female UTA students is by all means a positive change. Also, results of previous investigations prove that regular leisure time physical activity in older age produces strong and long-term antidepressant effects and considerably reduces susceptibility to stress $[4,20,22-26]$. The findings of the present study are in line with the outcomes of earlier studies - participation of elderly persons in regular physical activity led to a decrease in depression levels and an increase in self-rated health [14,21].

The study sought to address the question of what factors determined the degree of changes in the quality of life in female UTA students. Demographic variables (age, education, financial situation) were found to be insignificant. An increase in the quality of life did not depend on perception ability of the women. Among physical health indicators, blood pressure proved significant. The lower the blood pressure, the higher the quality of life in environmental and social domains and the higher the indicator of self-rated health. Systolic blood pressure was also a negative predictor of the last two changes. It implies that regular activity (physical, cognitive and social activity) may prove more beneficial to healthier seniors. No studies were found that would seek predictors of life quality improvement in elderly individuals taking up various forms of activity.

A decrease in depression levels correlated positively with balance. One of the indicators of balance (right-leg stance with eyes closed) turned out to be a positive predictor of this change. Further research is needed to determine if the findings are generalisable or if they are only specific to this study. Results obtained by other researchers indicate that there exists a positive correlation between the participation in classes aimed at improving balance (e.g. pilates) and a decrease in the intensity of depressive symptoms and an increase in the quality of life in active women [27-29]. Furthermore, 
depressive symptoms increase the risk of falls and balance disorders in older age [30]. It is believed that positive effects of physical activity (including exercises that improve balance) on the reduction in the intensity of depressive symptoms in elderly persons stem from an increase in serotonin levels. An imbalance in serotonin levels may lead to balance disorders and may intensify symptoms of depression [31].

The lack of the control group represents a major limitation of the study. Although it seems highly unlikely, it cannot be ruled out that the changes observed resulted from the impact of variables that were not investigated, including spontaneous changes that occurred over time. Even if we assume that the changes took place as a result of participating in UTA classes, we cannot state which of the following factors is responsible for them: physical, cognitive or social activity. To address these questions thoroughly, it is necessary to carry out research using a full experimental design.
Another limitation is the fact that only women were included in the study. However, it reflects the reality, as there are hardly any men attending UTA classes.

To sum up, the findings of the present study suggest that participationinregularclasses atUTAmay contribute to an improvement in the quality of life, an increase in self-rated health and a decrease in depression levels. These benefits may depend on health state and physical fitness of participants prior to the study. Nevertheless, caution should be exercised regarding cause-and-effect conclusions due to a quasi-experimental study design and when it comes to generalising the results because of the small group size.

Emphasising positive correlations between physical activity levels and the quality of life (especially psychological and physical aspects) may become a motivating factor for elderly persons to increase their daily physical activity levels. Therefore, it is worth implementing physical activity in programmes aimed at activating ageing adults to take care of their psychological well-being and reduce the risk of depression $[13,22]$.

\section{References}

1. McNaughton SA, Crawford D, Ball K, Salmon J. Understanding determinants of nutrition, physical activity and quality of life among older adults: the Wellbeing, Eating and Exercise for a Long Life (WELL) study. Health Qual Life Out. 2012:109-17.

2. Karimi M, Brazier J. Health, Health-Related Quality of Life, and Quality of Life: What is the Difference? PharmacoEconomics. 2016;34:645-9.

3. Martinez-Martin P, Prieto-Flores ME, Forjaz MJ, Fernandez-Mayoralas G, Rojo-Perez F, Rojo JM, et al. Components and determinants of quality of life in community-dwelling older adults. Eur J Ageing. 2012;9(3):255-63.

4. Sawicka EA, Ehlers DK. Effects of a randomized exercise trial on physical activity, psychological distress and quality of life in older adults. Gen Hosp Psychiatry. 2017;49:44-50.

5. Santacreu M, Bustillos A, Fernandez-Ballesteros R. Multidimensional/ Multisystems/ Multinature Indicators of Quality of Life: Cross-Cultural Evidence from Mexico and Spain. Soc Indic Res. 2016;126:467-82.

6. Couture EM, Chouinard MCh, Fortin M, Hudon C. The relationship between health literacy and quality of life among frequent users of health care services: a cross-sectional study. Health Qual Life Out. 2017;15:137-43.

7. Kossakowski JJ, Epskamp S, Kieffer JM, van Borkulo CD, Rhemtulla M, Borsboom D. The application of a network approach to Health-Related Quality of Life (HRQoL): introducing a new method for assessing HRQoL in healthy adults and cancer patients. Qual Life Res. 2016;25:781-92.

8. Mujica-Mota RE, Roberts M, Abel G, Elliott M, Lyratzopoulos G, Roland M, Campbell J. Common patterns of morbidity and multi-morbidity and their impact on health-related quality of life: evidence from a national survey. Qual Life Res. 2015;24:909-18.

9. Trombetti A, Reid KF, Hars M, Herrmann FR, Pasha E, Phillips EM, Fielding RA. Age-associated declines in muscle mass, strength, power, and physical performance: impact on fear of falling and quality of life. Osteoporos Int. 2016;27:463-71.

10. Prieto-Flores ME, Fernandez-Mayoralas G, Rosenberg MW, Rojo-Perez F. Identifying connections between the subjective experience of health and quality of life in old age. Qual Health Res. 2010;20(11):1491-9.

11. Steptoe A, Deaton A, Stone AA. Subjective wellbeing, health, and ageing. Lancet 2015;385:640-48.

12. Quintal Gouveia ER, Gouveia BR, Ihle A, Kliegel M, Maia JA, Bermudez i Badia S, Freitas DL. Correlates of health-related quality of life in young-old and old-old community-dwelling older adults. Qual Life Res. 2017;26:1561-9.

13. Koolhaas CM, Dhana K, Van Rooij FJA, Schoufour JD, Hofman A, Franco OH. Physical activity types and health-related quality of life among middle-aged and elderly adults: the Rotterdam study. J Nutr Health Aging. 2018;22(2):246-53.

14. Leś A, Guszkowska M, Kozdroń E, Niedzielska E, Piotrowska J, Krynicki B. Mood of the Third Age University students and its correlation. Gerontol Pol. 2017;25:20-7. 
15. Hajian-Tilaki K, Heidari B, Hajian-Tilaki, A. Health Related Quality of Life and Its Socio-Demographic Determinants among Iranian Elderly People: a Population Based Cross-Sectional Study. J Caring Sci. 2017;6(1):39-47.

16. Escuder-Mollon P, Esteller-Curto R, Ochoa L, Brdus M. Impact on Senior Learners' Quality of Life through Lifelong Learning. Procd Soc Behv. 2014;131:510-6.

17. Lejzerowicz-Zajączkowska B, Hajduk P. Aktywność fizyczna osób starszych jako działalność edukacyjno-interwencyjna. Prace Naukowe Akademii im. Jana Długosza w Częstochowie Kultura Fizyczna. 2017;4(16):109-21.

18. Halaweha H, Willen C, Grimby-Ekmanb A, Svantesson U. Physical Activity and Health-Related Quality of Life Among Community Dwelling Elderly. J Clin Med Res. 2015;7(11):845-52.

19. Haider S, Luger E, Kapan A, Titze S, Lackinger Ch, Karin E. Schindler KE, Thomas E. Dorner TE. Associations between daily physical activity, handgrip strength, muscle mass, physical performance and quality of life in prefrail and frail community-dwelling older adults. Qual Life Res. 2016;25:3129-38.

20. Chodzko-Zajko WJ, Proctor DN, Fiatarone Singh MA, Minson ChT, Nigg CR, Salem GJ, et al. Exercise and Physical Activity for Older Adults. Med Sci Sports Exerc. 2009:1510-30.

21. Niedzielska E, Guszkowska M, Kozdroń E, Leś A, Krynicki B, Piotrowska J. Quality of life and its correlates in students of a university of the third age. Pol J Sport Tourism. 2017;24:35-41.

22. White RL, Babic MJ, Parker PD, Lubans DR, Astell-Burt T, Lonsdale Ch. Domain-Specific Physical Activity and Mental Health: A Meta-analysis. Am J PrevMed. 2017;52(3):653-66.

23. Yoshida Y, Iwasa H, Kumagai S, Suzuki T, Awata S, Yoshida H. Longitudinal association between habitual physical activityand depressive symptoms in older people. Psychiatry Clin Neurosci. 2015;69: 686-92.

24. Reid KJ, Baron KG, Lu B, Naylor E, Wolfe L, Zee PC. Aerobic exercise improves self reported sleep and quality of life in older adults with insomnia. Sleep. 2010;11(9):934-40.

25. Lopes AA, Lantz B, Morgenstern H, Wang M, Bieber BA, Gillespie BW, et al. Associations of self-reported physical activity types and levels with quality of life, depression symptoms, and mortality in hemodialysis patients: the DOPPS. Clin J Am Soc Nephrol. 2014;9(10):1702-12.

26. Wołoszyn N, Wiśniowska-Szurlej A, Sozański B. An assessment of the relationship between the level of physical activity and the risk of falls and depression in elderly adults aged 60-75 years from the Podkarpackie region. Adv Rehab. 2018;2:41-8.

27. Mokhtaria M, Nezakatalhossainib M, Esfarjanic F. The effect of 12-week pilates exercises on depression and balance associated with falling in the elderly. Procd Soc Behv. 2013;70:1714-23.

28. Correa J, Cunha FA, Pires TH, Giani T, Ferreira MA, Dantas E. Effects of distinct physical activity and meditation programs on quality of life and depression levels in active elderly women. J Hum Movement Stud. 2009;23:1-13.

29. Skwiot M, Juśkiewicz-Swaczyna B. Physical activity and quality of life according to students of the University of the Third Age. Adv Rehab. 2017;4:45-56.

30. Kamińska MS, Brodowski J, Karakiewicz B. Fall Risk Factors in Community-Dwelling Elderly Depending on Their Physical Function, Cognitive Status and Symptoms of Depression. Int. J. Environ. Res. Public Health. 2015;12(4):3406-16.

31. Hassan EAH, Amin MA. Pilates Exercises Influence on the Serotonin Hormone, Some Physical Variables and the Depression Degree in Battered Women. World J Sport Sci. 2011;5(2):89-100. 